\section{A A} oN

\section{THE DIAGNOSIS AND TREATHENT OF RHEUMATIC HEART DISEASE IN ITS EARLY STAGES.}

Defivelied bFFore the North Glamorgax AND Breckiock Division

BY

\section{CARFY F. COOMBS, M.D., F.R.C.P.,} PIYYSICIAN, BRISTOL GENERAL hospJTAL.

We have, I believe, learnt from the study of the rheumatic infection a good deal that is applicable to a comprohension of the general behaviour of infective disease. We have gradually been compelled to realize that this, one of the deadliest forms of disease, is provoked by micro-organisms that do not seem to be radically different from the streptococci that inhabit the normal mouth. Thus we have been once more reminded of the fact that the soil is as important as the seed. A healthy child does not become rheumatic because of any dire bacterial visitation, but because defects of inheritance and of environment combine to lay him open to invasion by organisms that the healthy child is able to resist. It seems certain that in at least a third of all cases this invasion takes place through the tonsils. In this proportion the opening of the campaign announces itself in a frank attack of tonsillitis. IVhat are we to say of the rest? It is probable that in some, if not in all, the infection slips in through the tonsils without exciting any perceptible protest at the site of entry. Some observers think that they have detected gastro-intestinal disturbances which mark a transgression of the Jymphoid areas of the bowel by the rheumatic streptococci, but this has not been my experience, though $I$ have been on the look out for these phenomena.

Two-thirds of the rheumatic children appear to be first infected between the ages of 5 and 15, and a large proportion of them are drawn from the elementary school population. We are in the midst of an inquiry into the nieaning of these facts-an attempt to find out why these children, and not others, are damaged-in Bristol, with the three neighbouring counties, and as this is not yet complete I shall make no comment, except to remark that so far we have not discovered anything likely to help us in the treatment of the child who is already rheumatic. It would be a great relief to find that these children are infected because of some definite lack or defect, such as an avitaminosis or an endocrine shortage; both of these views have been advocated by experienced observers, and wo can only hope that they. will succeed in persuading us to agree with them. At the moment, however, we do not seem to have gained anything applicable to the treatment of the rheumatic child from either of these schools.

I am going to assume, in this brief sketch, that the lesions of rheumatism in childhood are provoled by the immediate action of organisms which are themselves present in the injured tissues. The alternative view, that it is the toxins only and not the organisms themselves, does not appear to me to cover all the facts. Organisms have been grown from the pericardial sac, the subcutancous node, the cerebro-spinal fluid, and so forth; and if we accept any of the bacteriological evidence about the disease we must a!so accept these findings. There is, then, an actual bacteriaemia.

About the lesions we are in no doubt. The principal tissues attacked are the heart, the joints, the meninges, and the subcutaneous tissues. Recent workers have shown that the lesions are more widely scattered than we used to teach. I may refer you to a recent paper by A. F. Bernard Shaw as an illustration of these newer views, to the work of Naish and Fraser on the pulmonary lesions of acute rheumatic infection, and also to Vincent Coates's papers on the prevalence of small subcutaneous nodulcs in these children. The damage done is therefor: more widely diffused than was at one time thought.
Another fact that is more and more impressed on me by extended clinical and pathological observation is the persistence of the infection. Formerly we thought of the course of the disease in terms of a series of periods of activity, separated by intervals of quiescence. I am learning to think that these intervals, during which there is neither fever nor any other clinical sign of active infection, are novertheless spent by the infective agent in a kind of subdued but not suspended animation. In order to unmask these activities Dr. Perry has conducted a series of observations on the lencocyte picture of rheumatic carditis in childhood, but without discovering any change that we can depend on to betray the presence of progressive infection. What one notices as undeniable proof of this progress is that a child whose general condition is fair, his temperature normal, his cardiac signs unaltered, is nevertheless found after a period of apparently uneventful weeks to have definitely worsened, and the heart, examined post mortem, if this deterioration should end fatally, displays unmistakable proof of infection which must have been active for weeks before death.

These two new lessons, then, we have to assimilate: the infection is more widespread and also more persistent than we had supposed. Wo may perhaps limit oursolves here to a brief notice of the cardiac lesions. These are manifestly distributed along the course of the coronary arteries and their finer ramifications, so that we meet them wherever we look in the tissues of the heart, whether in the pericardial covering, the endocardial lining, or the myocardial mass. It is by their action on the muscle itself that the bacteria of rheumatic infection involve their victim in immediate danger; for example, on the day of writing I was told of a child who hac? died in the lospital, within a weck of the onset of his illness, with acute ventricular dilatation and failure. Many of those who escape this fate sulvive for a few vears only, and then succumb to a recrudescence of the infection, which deprives the ventricular muscle of such little margin of safety as had been spared to it by previous activities. Of those who are more fortunate than this, a majority pass on into a condition of permanent valvular disease which has the effect of limiting the scope and length of life. What is to prevent this? Can it be in any way prevented? Some vears ago, when Dr. Pornton ${ }^{3}$ consented to write an introduction to the book of which I have already spoken, I was greatly struck by one comment which he made, to the effect that an interesting result from the following up of a group of cases of undoubted early cardiac rheumatism was the discovery that a quarter of them lost all signs of the disease in fifteen vears. Dr. Poynton went on to say that this was in accord with his own experience. He had known recovery from undoubted carditis so complete as to throw doubt on the validity of the original diagnosis. "Such facts," he concluded," are very comforting to those who believe in the future of prevention."

Now, since this was written we have in Bristol had over two year's' experience of a cardio-rheumatic clinic. In that period we-Dr. Perry and I-lave seen 1,100 children referred to us by the school medical service for an opinion on the state of the heart. Of these, 653 have been judged by us to be suffering, from rheumatic heart disease. I can give you no statistic's in support of the statement that this organization is doing good in the arrest of the disease in an appreciable proportion of these children; yet $I$ am convinced that this statement is true, convinced enough to derive encouragement for the prosecution of a campaign against an enemy that sometimes looks invincible. Now there is no secret or special means by which this progress is achieved. It depends on the same principles as those which ought to guide us in the fight against all infections - early diagnosis and persevering treatment.

If rheumatic injury to the heart is to be recognized in an eariy stage, it cain only be done by remembering that srmptons of cardiac insufficiency do not appear till the lesions are already established and severe. This is merely an illustration of two great principles of pathology: the first, that no lesion of any organ can be considered apart from disease in the rest of the body; the second, that in 
every vital organ there is so wide a margin for emergencies that symptons of imperfect function do not appear till the disease has been in progress some time, long enough to encroach seriously on that margin. If we apply these principles to the consideration of rheumatic carditis, we shall note, first, that hints as to the possibility of rheumatic infection of the heart may be furnished by symptoms of other rheumatic phenomena; and second, that constitutional symptoms are likely to precede those which indicate a decrease in the mechanical efficiency of the heart.

Coning to details, we may say that there are four different approaches to a diagnosis of cardiac rheumatism in its early stages.

1. The easiest of these is that in which the rheumatic infection declares its presence within the body by provoking either arthritic pains or chorea. Even this is not always as easy as it sounds. Sometimes, for example, an attack of what looks like acute rheumatism turns out to be something else, such as osteo-myelitis. More often, however, the joint pains themselves are so trivial that the child makes but little complaint, and that little receives no notice. One cannot but feel some sympathy with this point of view. We do not want to encourage children to make a fuss over every little ache or pain, and it is not easy to tell parents how to lay stress on the pains that matter, while ignoring those that do not. Perhaps one might say this: that pain persisting more than a day, or pain which malkes the child lame, ought to be noticed; also that if the child looks ill or has a rise of temperatnre. however small, with the pain, the doctor ought to be called in.

Then, again, supposing there is no doubt as to the rheumatic nature of the illness, how are we to know whether the heart is damaged or not? On this point I am inclined to say that every child who has rhemnatic polyarthritis that can be recognized as such may be assumed to have an infected heart also, even if there are neither symptoms nor signs of this. I cannot recall any example within my own observation of a child who passed through an attack of articular rheumatism without showing either at the same time, or later on, evidences of cardiac rheumatism. With chorea it is different. Many child!en develop, sustain, and recover from an attack of chorea without displaying any evidence of cardiac infection. It is to be remembered, however, that if these more fortunate ones be followed up, a considerable proportion will be found later to exhibit signs of cardiac infection. Of the other rheumatic phenomena I need say little, except to remind you that the subcutaneous node is always to be regarded as a proof that the body is heavily infected. If these nodes are found, therefore, it must be assumed that carditis is sure to develop also, and that it is likely to be severe.

2. Rhcumatic carditis is so often preceded by an attack of tonsillitis that one ought to consider repeated examination of the heart (and also, one may add, of the urine) an essential part of the care of any child with inflamed tonsils. It is not enough to do this throughout the attack of tonsillitis itself. Often the signs of cardiac inflammation do not appear till a week or more after the tonsillitis and its constitutional symptoms appear to have died down. If possible, therefore, one ought to sce children convalescent from tonsillitis a few days after every obvious symptom lias cleared up.

3. The most important of all these methods of securing an early diagnosis of cardiac rheumatism is that which it is hardest to practise and easiest to forget. It turns on the fact that the heart may become definitely and permanently damaged by rheumatic. infection without any other perceptible manifestation of the infection. It is perhaps putting it too strongly to say that one ought to think of carditis as the disease, and arthritis, chorea, and so on, as the complications. That is not a true account of the pathology of this infection, which onght rather to be looked or as causing four chief manifestations: carclitis, polyarthritis, chorea, and nodes. Yet from the point of view of their ultimate importance these other phenomena are almost negligible. Their real significance is that of indicators warning us of the possibility-indee?, as we have seen, of the probability - of a concomitant carditis. The particular difficulty that we are now discussing is that of the child whose heart is infected before thcse other phenomena have developed; incleed, in many cases they never develop at all, and the cardiac lesion is not found until the chest is examined, either as a result of some other illness or in the course of a routine inspection such as that of the school medical service. The work of which I spoke just now has convinced me that this group of cases is a large one. During the same period that has brought to light in the elementary schools' $a$ total of 653 cascs of cardiac rheumatism we have been receiving, through a sristem of voluntary effort, reports of cases arising in the private practices of nedical men within the area under review. In Bristol we have had 238 of these cases reported, and $I$ do not believe that many cases have escaped detection either by the medical men who have so kindly furnished these reports or by the school medical officers. It seems, therefore, as if for every ease of rheumatic carditis that makes itself known to a medical man at the time when it is established there are two that are not found until the child is examined as a part of the school routine. This is a serious state of affairs, and I shall make some observations on it again presently. Here let me sav only this, that the earliest symptoms of such cases are not cardiac but constitutional-loss of appetite, vague seediness, increasing pallor, and, above all, loss of weight. The practical lesson to be learnt is that every child brought to us for these vague symptoms nust be stripped and examined thoroughly. I do not say that this will do away with the cielay in diagnosis that results in the establishment of serious disease before its presence is first recognized. It would, however, reduce appreciably the number's of these overlooked lesions.

4. Finally, there are a few children to whom we are first called because of cardiac symptoms. These fall into two groups. First, there are chitdren who are taken with an acute febrile illness with chest symptoms. Not infrequently the first diagnosis made is that of pneumonia or plenrisy, and it is only aftér a few days that the development of a pericardial ruh, or a rapid widening of the area of cardiac dullness, teaches us to look to the heart for an explanation of the illness. Then there is another group of children, who are brought to us because of breathlessness. This is a very small group. It takes a severe degree of cardiac disease to make a child visibly breathless. We may say, therefore, that whether the carditis is acute or chronic it must be severe if it is to produce symptoms of cardiac insufficiency, and it would therefore be a grave mistake to regard such symptoms as essential to a diagnosis.

To sum up what has so far been said as to the possibility of an early diagnosis: We ought to examine thoroughly every sick child that is brought to us; we ought to examine early, thoroughly, and repeatedly every child with tonsillitis; and we ought to regard as a probable cardiac victim every child with any definite manitestation of rheumatic infection.

Before we leave this subject of early diagnosis you mav be interested by a few observations on the physical signs which may be relied on to indicate to us the existence of a carditis. As in so many of our attempts to make an early diagnosis of visceral disease, we have to steer a narrow and difficult course between two dangers-that of overlooking the lesion, on the one hand, and, on the other,
that of being deceived by some counterfeit.

My first point is that arrhythmia in a child means nothing unless it is supplemented by signs of serious organic heart disease. An cxaggeration of the physiological sinus irregularity is seen in most children at one time oranother, and particularly during convalescence from an acute illness. To regard it as a sign of cardiac disease is therefore a serious mistake. It is true that very rarely one sees the total arrhythmia of auricular fibrillation, and more rarely still arrhythmia due to abnormalities of auriculo-ventricular conduction, in children with rheumatic heart disease; but this is only in the presence of very acute or serious phases of the clisease. We may therefore take it that arryythmia alone is not to be accepted as the basis of a diagnosis of organic hoart disease in childhood.

It is almost as true to say that a murmur alone is not to be regarded as cvidence of cardiac disease in childhood. 
There is one exception to this-the diastolic murmur of aortic incompetence may, very rarely, be the only sign of cardiac disease in a rheumatic child. Jven this exception is so rare that we might almost accopt my dictum as it stands. If we amend it to run thus, " $A$ systolic murmur alone is not to be regarded as evidence of cardiac disease in childhood," we shall not be overstating the case. 'The earliest phase of cardiac rheumatism that can be diagnosed with absolute confidence is that in which there is a coincidence of four physical signs: increase in the area of impulse in the leftward direction; accentuation of the first sound at the apcx; a systolic murmur limited to, or at all crents maximal at, the apex; and an accentuation of the pulmonic second sound. To make a diagnosis in the presence of these signs is an easy matter. Even if there is no rheumatic history and the child is free from symptoms of any kind at the time, the discovery of these signs justifies a diagnosis of cardiac rheumatism.

What is not so easy is a right decision as to children who display part only of this picture. There are two principal groups exemplifying this kind of difficulty. Among children of school age systolic murmurs are very common. Sometimes they are heard at all parts of the precordium; sometimes at basic areas only; sometimes at the middle of the precordium, at the inner end of the fourth left space sometimes at the apex only. I wish there were time to discuss all these in detail, but this alone would occups the whole of our available time if we were to do it thoroughly. It is a little disturbing to find how much uncertainty still surrounds the explanation of so simple a physical sign as the systolic murmur. Those of you who would like to read something more of the systolic murmurs heard in childhood will be interested by a paper published in the Archices of J)isease in Childhood by Dr. Dunstan Brewer." This includes some valuable observations on the course of murmurs of the "doubtful" or "haemic" type, which showed that a majority were found to disappear if the children were re-examined over a period of years.

All that I need add here to the general dictum as to the unwisdom of making a diagnosis of organic disease on the strength of a systolic murmur alone is that, first, a murmur heard at the apex alone, even if unsupported by other signs, justifies a waiting attitude; and also that, even if the murmur is general, heard all over the heart, this also may be regarded with suspicion if it arises in the appropriate circumstances-for example, after an attack of tonsillitis or in a child with chorea. Speaking generally, the younger the child the more likely are these signs to prove evanescent. When they appear in a child of 10 or more, suspicion is more likely to pass into certainty. But, even so, we are not of ten justified, I think, in keeping a child in bed on the strength of the murmurs alone.

There is one little point that I think worthy of notice in relation to this question of systolic murmurs, and that is their reaction to a change of position. I find that it adds very little to the time spent in an exanination to observe this, if it is made a matter of routine to examine the child standing up first, then lying flat on his back, then ling on his left side with the heart underneath. The value of this routine lies in the fact that many oroanic murmurs heard at the apex are inaudible when the patient is standing, but are brought out clearly when he lies down flat, and even more so when he is on his left side.

There is much more that might be said about these murnurs, but I must devote a few moments to a consideration of the value of the other signs. Let me put it briefly thus-that an increased area of impulse by itself, even without alteration in the sounds, is to be treated with respect. If it is noted in a child who, there is reason to think, is the subject of recent and active infection, it is cnough to impose on us the duty of keeping the child in bed, or on light exercise, till we are satisfied that evidence of active infection is at an end. If it is found in a child who gives a history suggestive of previous though extinct rheumatic infection, it is a reason for re-examination from time to time over a period of twelve months at least. These precautions are all the more necessary if there are changes in the sounds-accentuation of the first sound at the apex or of the second sound at.the pulmonary base; or doubling of the second sound at the apex. I do not think we are called upon to regard these signs as evidence of a definite carditis, as it is clear from the course of a group of 34 cases of this kind-cases that I labelled " doubtful and suspicious" "_that the odds are against their evolution into serious organic disease. Of these 34 cases, 15 lost their signs entirely, 11 developed a nermanent valvular fibrosis, and 8 renained unchanged after a period of observation varying from five to fifteen years.

I find I have been betraved into the rery thing that I wished to aroid-I have said a great deal more about physical signs than about symptoms. It will be found that under the present conditions of practice the rhildren that we sce are those with symptoms. I wish it were possible to take a leaf out of the school medical service books, and get every child, whether ill or well, examined periodically by the family doctor. This may seem an absurd dream as things are at the moment, but $I$ believe it is not altogether outside the purvicw of practical politics.

Let me in conclusion devote a few minutes to a consideration of the principles of treatment of rheuniatic heart disease detected in an carly stage. It mav help to illustrate some of these principles if I mention that, of the 653 children with rhenmatic heart disease seen in the clinic to which I have referred, we have allowed two-thirds to continue attendance at school. More than half of these are allowed to attend only under restriction of exercise. Our reason for asking for this restriction is not that we fear mechanical overstrain of a damaged heart. We restrict excrcise in rheumatic infection of the heart just as we should in any other persistent infection, because we want the child to devote as much as possible of his phrsical energies to his fight against the infection. If their exercise could be adequately supervised I am sure it would be possible to give them a freedom in this respert that, under present conditions, seems imprudent; for the principle that underlies all our ideas as to treatment is that we are dealing with a disease in which periods of activity alternate with periods of quiescence. During quiescence restrictions are not necessary and may cven be harmful; while during the active phases the degree of treatment ought to be proportioned to the degree of activity. We are cautiously beginning to employ superrised exercise in convalescent cases.

Complete rest in bed is only adrised in about a tenth of the cases that come to us in the clinic. This we advise whencrer there is any symptom of active infection, such as fever, wasting, joint pains, or chorea-at all events at first. We shall probably increase the proportion of children recommended for institutional treatment if and when the accommodation can be found. This period of rest not only gires the patient a better chance of overcoming his infection; it also gires the doctor a better chance of assessing the degree of activity and deciding what to do. If the child shows continued signs of activity, or if the initial symptoms of infection are severe, prolonged rest is needed, cren up to six months in bad cases. The symptoms that make me most anxious, and therefore most insistent on the need for prolonged rest, are continued pallor and wasting, fever, nodes, chorea, recurring joint pains, and progress in the definition of the physical signs.

One might enlarge on the significance of ferer in this discase, but there is only time for one or two points. Two kinds of ferer are seen in-tlis disease. Sometimes an otherwise normal temperature is disturbed by periods of pyrexia varying from two or three days to as many weeks. These mark outbursts of infection so serere that they are not likely to be overlooked. The other kind of ferer is more insidious. The child shows an excessive daily fluctuation rising but little above the normal line, but persisting for weeks. This is associated with progressive injury to the cardiac tissues of a very damaging kind. In other cases, again, the absence of fever by no means proves an absence of active infection. Some of the worst cases run an afebrile course, which is perhaps a sign of unusually poor resistance. In such cases there is generally abundant evidence that matters are not going well; the child remains pale and thin, the cardiac signs 
are either stationary or ingravescent, and there are hints of circulatory failure such as faint cyanosis, increase in the size of the liver, puffiness under the eyes, and so forth. Fever, then, is not an infallible guide in the treatment of this disease. In search for some other guide Dr. Perry has made an extensive inquiry into the value of leucocyte counts, but here again we have been disappointed, as I have already said. It will be seen, therefore, that we find it impossible to lay down any rules as to the duration of rest in bed in this disease. What $I$ would suggest is that any febrile event of more than four days' duration indicates a subsequent rest of not less than four weeks. Return to activity after this must be gradual and tentative, and conditioned not only by what has happened during the period of rest, but also by the child's response to increasing exercise.

About the use of salicylates there is a wide diversity of opinion. It is useless to weigh the pros and cons here, for the evidence is so misty and inconclusive. My belicf is that it is practically always safe to give salicylates in big doses. Occasionally-in perhaps one case in a hundred-you find that it is doing harm, and then, of course, it must be stopped. Often it will be found that it is not doing good. Sometimes this is because the dose is too small, and sometimes again it is worth while to substitute some other preparation-for example, aspirin may suit a particular child better than the sodium salt. We find that 5 to 10 grains of the former, or 10 to 20 grains of the latter, seldom cause toxic symptoms, even if given every hour or two hours for more than a day at a time. We have tried all sorts of other plans designed to kill off the infection, for this, I suppose, is the way in which the salicylates act; but we have not found anything that can be proved to have the desired effect, and I am not going to weary you with a catalogne of our failures.

Similarly, we have experimented with many means of cnhancing the child's resistance, without much success. I feel sure that when the periods of rest are conjoined with free access to fresh air and sunlight, and with a liberal diet in which fats are given generously, the child gets on better. We have lately found it well to give cod-liver oil and iron to children even while they are still taking salicylates, and this I believe is worth bearing in mind. Tonsillectomy is thought by many experienced observers to be indicated as a routine measure. The evidence for and against this view is very difficult to appraise, and there is no time to attempt it here. Our own practice is to have tonsils removed if they are obviously diseased, if there is an associated adenitis, or if by reason of their size their removal would be indicated even apart from the coexistence of rheumatic infection. More than once I have seen a serere recrudescence of the infection follow an excision of tonsils which have recently been the seat of an acute inflammation, and it seems, therefore, that anything of this kind should be allowed plenty of time to settle down before operation is advised.

This account of treatment is very unsatisfactory, and seems to amount to nothing more than watching the course of a discase which we are powerless to arrest. Yet I feel sure that much is achieved merely by patience and perseverance in those homely measurcs by which we are accustomed to encourage the fight against bacterial activity. What we need is a clear realization of the tenacity and persistence of this infection. It is not a matter of days or even weeks, but of months or even years. One of the fruits of this attitude of mind is the increased provision for prolonged institutional treatment of these children, but even where this is not essential, or is impracticable, the mere fact that we realize the need for patience and perseverance in the application of an enlightened common sense to the management of this disease is going to make a sensible reduction in the number of cripples for which it is responsible.

REFERENCES.

Shaw, A. F. Bernard: Archives of Disease in Chitdhood, 1929, vol. 4, 155.

2 Perry, C. Bruce : Ibid., 1929, vol. 4, 247.

3 Poynton, F. J.: Rheumatic Heart Disease, by Carey F. Coombs, 1924, Introduction, $x x$.

- Brewer, Dunstan: Archices of Disease in Chillhood, 1928, vol. 3, 277.

- Coombs, Carey F. : Rheumatic Heart Disease, 1924, 269.

\section{An Àntress}

ON

\section{THE DIAGNOSIS OF EARLY JUVENILE RHEUMATISM.*}

REGINALD MILLER, M.D., F.R.C.P.,

PHYSICIAN, AND PHYSICIAN IN CHARGE OF THE RHEUMATISM

SUPERVISORY CENTRE, PADDINGTON GREBN CHILDREN'S HOSPITAL, LONDON.

Juvenile rheumatism is an environmental disease, and until the mass production of it can be stayed by public health measures the best contribution to the problem which can be made by us as individual clinical physicians is to get each separate case of rheumatism in a child diagnosed, treated, and under supervision at the earliest possible stage of the disease. It is to this matter that I now direct attention, and $I$ emphasize at the outset that the diagnosis of early rheumatic infection in a child is at least as difficult a matter as that of early tuberculosis.

Two preliminary questions arise. First, have we a chance of diagnosing rheumatism before serious harm has occurred in the child's heart? Secondly, if we do make such an early diagnosis, have we a sporting chance of preventing serious heart disease?

In answer to the first question it is undoubtedly true that we have a chance of early diagnosis. However abrupt the onset of a serious attack of rheumatism may appear to be-and we all know how rapid, how ruthless, and how overwhelming the onslaught of rheumatic infection can beit is almost invariably the case that premonitory symptoms lrave preceded the attack for weeks or months, and that they have been overlooked, neglected, or misinterpreted. Those who doubt this have not taken their clinical histories correctly; in nearly all cases there is this premonitory stage. And if we make a diagnosis in this premonitory stage, shall we have a chance of preventing more serious attacks, particularly the more serious forms of heart disease? Frankly I do not see why we should doubt it. It is in line with what we do in other diseases. We can remove foci of infection, combat the environmental factors, and protect against exciting-causes of acute attacks. Sometimes we shall fail; perhaps we start too late, perhaps the environment is too heavily against us, perhaps there are factors we cannot control or even recognize, but I see no reason to doubt that often we do really help. Some require mathematical proof of this: they will not get it; you cannot make a statistical comparison of known results with unknown possibilities. The real proof comes to the clinical worker who is supervising his own patients. When he sees, as I have seen in dozens of instances, the removal of tonsils and the adoption of other measures lead to increased weight, strength, and colour, and the gradual loss of rheumatic pains, he will not doubt that in a certain proportion of cases he has actually prevented serious rheumatism and heart disease.

\section{Early Diagnosis.}

Before I come to the study of the prodromal symptoms of juvenile rheumatism there are two factors of possible diagnostic value to be considered-the rheumatic diathesis and the so-called pre-rheumatic child. Are these realities? Can we recognize them? Are they an aid to diagnosis?

\section{The Rheumatic Diathesis.}

Some recent writers have professed great faith in the rheumatic diathesis, in the sense that they think that certain children, if they lose good health, turn naturally into cases of rheumatism. I do not share this view. The older physicians laid great stress upon the familial tendency towards rheumatism, and this rather tended to a belief in a rheumatic diathesis. Recent investigations, undertaken on very accurate and strict lines, show that the family tendency has been exaggerated and is not more than can be accounted for by the frequency of the disease and 